\title{
A POLÍTICA DE COTAS NA AMÉRICA LATINA COMO IMPULSORA DA REPRESENTA- ÇÃO FEMININA NA CÂMARA BAIXA
}

\author{
Ellen da Silva ${ }^{1}$ \\ Isadora Lopes Harvey ${ }^{2}$
}

Resumo: Nos anos 1990, a pressão externa da comunidade internacional, combinada com a pressão interna dos movimentos feministas, gerou ambiente propício para a reflexão de políticas públicas sobre igualdade de gênero em diversos países latino-americanos. Neste contexto, foi gestada a política de cotas legislativas para inclusão de mulheres na política institucional na região. A política de cotas, que teve início na Argentina de 1991, foi implementada nos anos que se seguiram em mais 14 países. É nesse sentido, e a partir de literatura atinente, que o presente trabalho expõe os processos em torno do surgimento de cotas legislativas; assim como seus principais resultados e desafios na mencionada região. A relevância desta empreitada reside na necessidade por um diagnóstico atualizado sobre cotas, em nível regional. Ainda que haja vasta literatura sobre o tema, em sua maioria, versam sobre experiências nacionais. Os resultados encontrados no decorrer deste trabalho apontam que, de modo geral, a representação feminina cresceu nos parlamentos da região. No entanto, aponta também a discrepância de intensidade entre cada país, assim como a predominância de sucesso em democracias que contam com mandatos de posição, magnitude em distrito eleitoral maior e listas fechadas e bloqueadas. Palavras-chave: Cotas Legislativas, América Latina, Mulheres no Parlamento.

\begin{abstract}
During the 1990s external pressure from the international community along with internal pressure from feminist groups created an environment ripe for reflection about public policy as it relates to gender equality in several Latin American countries. It is within this context that many Latin American countries adopted legislative quotas for the inclusion of women in institutional politics. The first country to adopt the measure within the region was Argentina in 1991, followed by 14 other Latin American countries. With this in mind and based on the relevant literature, the study at hand explores the ways in which legislative quotas emerged as well as their main results and challenges in the region. The importance of this endeavor relies in a recent regional diagnosis about quotas. Although there is a vast literature on the topic, it normally consists only on national experiences. The results show that, in general, female representation grew in the parliaments, albeit with varying intensity. Furthermore, the results also show that democracies with mandate of position, larger electoral districts, and closed or blocked lists had more success increasing female representation.
\end{abstract}

Key-Words Legislative Quotas, Latin America, Women in Parliament.

Resumen: En los años 1990 la presión externa de la comunidad internacional combinada con la presión interna de los movimientos feministas generó un ambiente propicio para la reflexión de las políticas públicas sobre la igualdad de género en diversos países latinoamericanos. En este contexto fue gestada la política de cuotas legislativas para la inclusión de las mujeres en la política institucional en la región. La política empezó en Argentina en el 1991, y en los años que se siguieron fue implementada en más 14 países. Debido a esto, a partir de la literatura del tema, el presente trabajo expondrá como surgieron las cuotas legislativas, sus principales resultados y desafíos en la región. La relevancia de este ejercicio está en hacer un diagnóstico reciente y regional sobre las cuotas. Además de existir una vasta producción académica sobre el tema, generalmente ésta refiera las experiencias nacionales. Los resultados enseñan que, de modo general, la representación femenina creció en los parlamentos de la región, pero en intensidades muy distintas, obteniendo más éxito en las democracias que cuentan con el mandato de posición, la magnitud de distrito electoral más grande y la lista cerrada y bloqueada.

Palavras-Clave: Cuotas legislativas, Latinoamérica, Mujeres en el Parlamento.

\section{INTRODUÇÃO}

Questionando o papel desempenhado pelas mulheres na sociedade, o feminismo foi responsável pelo lançamento de novos paradigmas teóricos, sociais, políticos e culturais. Através da luta de sufragistas - mulheres da primeira onda feminista - pudemos ampliar o conceito de democracia; permitindo o voto de mulheres e de homens. Sob o slogan "O pessoal é político", a segunda onda representou a busca por emancipação da esfera doméstica; aproximando as fronteiras entre o público e o privado, e mostrando que as relações de

\footnotetext{
${ }^{1}$ Mestranda em Ciências Sociais no Centro de Pesquisa e Pós Graduação sobre as Américas da Universidade de Brasília-UNB. Graduada em Ciências Sociais pela Universidade Federal o Paraná - UFPR. Email: ellensilva1990@gmail.com.

${ }^{2}$ Mestra em Ciência Política pelo Instituto de Ciência Política da Universidade de Brasília-UNB. Graduada em Ciência Política pela Universidade Federal do Estado do Rio de Janeiro - UNIRIO. Email: harveyisadora@gmail.com.
} 
poder existentes em ambas tornam a discussão de uma, imprescindível à outra. Como parte da emancipação do âmbito doméstico, feministas latino-americanas também foram em busca de representação institucional. Articulando-se e contando com o apoio de organismos internacionais, que também pautavam questões de gênero, pressionaram a aprovação de políticas públicas que visassem a equidade de gênero nos países da região.

Mantendo essa trajetória em mente, o presente trabalho tem por objetivo expor o surgimento das cotas legislativas, políticas públicas que buscam inserir mulheres no parlamento; seus principais resultados e desafios. A discussão aqui proposta visa a soma de estudos de gênero focados em políticas públicas para a equidade com estudos que versem sobre a qualidade de democracias latino-americanas, e também a discussão de em que medida os Estados e seus aparatos têm garantido a representação política de suas cidadãs e cidadãos.

Para cumprir com seus objetivos, o trabalho está dividido em três partes. Na primeira parte, o contexto que possibilitou as cotas na América Latina, será feita uma breve contextualização histórica, visando ressaltar alguns elementos-chave que permitiram a ascensão de políticas públicas de gênero na região. Durante a segunda parte, uma visão panorâmica da região: a política de cotas na América Latina, apresentaremos a trajetória da política de cotas nos legislativos nacionais, assim como seus principais resultados. Por fim, na terceira e última parte, os principais desafios da implementação de cotas na América Latina, serão listados os principais desafios para a implementação dessa política na região.

\section{O CONTEXTO QUE POSSIBILITOU AS COTAS NA AMÉRICA LATINA}

Em toda a América Latina, o sufrágio feminino - direito mais elementar de cidadania - tardou a ser efetivado. O primeiro país que permitiu mulheres a votarem e serem votadas foi o Equador, em 1929. Embora logo depois, em 1932, Brasil e Uruguai também tenham aderido à medida, o restante da região custou a atingi-la. Apenas em 1961, Paraguai e El Salvador completaram a lista de países latinos a garantir esse direito.

Como afirma Saffioti, "Em nenhum país do mundo pode-se falar em feminismo no singular" (1986, p. 105 apud BITTENCOURT, 2015, p. 198). Nesse sentido, embora vivenciem experiências comuns à região, encontramos forte multiplicidade de organizações e posicionamentos teóricos dos movimentos feministas ao longo da história da organização de mulheres latinas.

Nas décadas de 60 e 70, a América Latina encontrava-se tomada por ditaduras e guerras civis. Consequentemente, a repressão na região impediu que as reflexões sobre questões de gênero tivessem espaço nas universidades; transportando a demanda para o centro de discussões em movimentos feministas. Muito se discutia os papeis sociais determinados às mulheres e homens; o mundo do trabalho; a família; as normativas da sexualidade e da reprodução (BAREIRA, 2013) - demandas fundamentais na luta contra os regimes ditatoriais vivenciados na época.

Os anos subsequentes, como veremos no excerto a seguir, foram fundamentais para uma expansão das bases e que compunham os diversos movimentos feministas:

Os anos 1980, marcados por uma opressão estatal brutal e um empobrecimento crescente, apresentaram novas oportunidades e desafios para a criação de um movimento feminista de bases mais amplas, à medida que milhares de mulheres começaram a se mobilizar politicamente - mesmo que não necessariamente como feministas - como resposta a crises econômicas, à repressão política e às violações dos direitos humanos. Em contraste à face branca/mestiça e de classe média do feminismo nos seus primeiros tempos, o movimento de mulheres dos anos 1980 floresceu com uma composição predominante de mulheres pobres, trabalhadoras e/ ou negras e indígenas. (ALVAREZ et al. 2003, p. 547-548). 
Os processos de redemocratização trouxeram uma nova dinâmica para os diversos movimentos feministas da região, que passaram a atuar cada vez mais na máquina do Estado. Um exemplo disso seria o aumento de ONGs e instituições que focavam na produção de políticas públicas. Neste sentido os enfrentamentos nas ruas, a movimentação de grandes contingentes de mulheres e de profundo questionamento do Estado ficou em segundo plano. (BITTENCOURT, 2015, p. 207-208)

Além da movimentação interna de feministas em cada país latino, concomitantemente, a agenda internacional contra a desigualdade de gênero, efervescia. Em 1975, na Cidade do México, acontecia a I Conferência Mundial sobre as Mulheres. O evento contaria ainda com mais três edições em Copenhague (1980), Nairóbi (1985) e Beijing (1995)³. Além da Convenção Contra Todas as Formas de Discriminação Contra as Mulheres, em 1979 (ARCHENTI, 2007). Em 1981, na Colômbia, também se iniciava I Encontro Feminista Latino-Americano e do Caribe. O primeiro de outras doze edições; Peru (1983), Brasil (1985), México (1987), Argentina (1990), El Salvador (1993), Chile (1996), República Dominicana (1999), Costa Rica (2002), Brasil (2005), Cidade do México (2009), Colômbia (2011) e Peru (2014) ${ }^{4}$.

Com o início dos anos 90, redes centradas em políticas tiveram aumento de influência e visibilidade significativas, em grande parte como resultado do crescente envolvimento dos feminismos latino-americanos e caribenhos com os processos de conferências da ONU supracitados (ALVAREZ et al., 2003). Foi, portanto, este fervor internacional que ajudou a compartilhar e legitimar outras tantas questões de gênero em diferentes contextos nacionais e internacionais. A visibilidade adquirida pela pauta feminista foi igualmente fundamental para que os estados membros da ONU se comprometessem a lutar pela superação da discriminação de gênero. Através da distribuição de recursos humanos e materiais de apoio às atividades de promoção à equidade, o sistema ONU passou a dedicar atenção especial ao tema (VALDEZ, 2007).

A pressão externa da comunidade internacional somou forças à pressão interna dos movimentos feministas e gerou um ambiente propício para a reflexão de políticas públicas pensadas para as mulheres em governos latino-americanos. A expectativa gerada era de que a pressão internacional pudesse ser canalizada nos governos nacionais e locais, a fim de assegurar a implementação de legislações e programas de apoio aos direitos das mulheres. Acompanhando esse movimento, surge também uma sinergia do meio acadêmico, natural da necessidade de recrutar especialistas que produzissem o conhecimento indispensável para execução dessas políticas. Na sequência, vieram estudos periódicos que se propunham a analisar o desempenho das iniciativas.

Fatores internacionais, mais notadamente as conferências da ONU nos anos 1990, reforçaram o crescente direcionamento de muitos grupos nacionais para a elaboração de políticas públicas. A participação efetiva no sistema da ONU exigia habilidades cada vez mais especializadas, mais recursos materiais, e alianças com organizações governamentais e instituições internacionais. Além disso, essa participação foi em grande parte financiada por agências de cooperação internacional multilaterais, bilaterais e não governamentais. Já predispostas a financiar organizações com uma estrutura e orientação mais profissionais (e às vezes governamentais), as agências privilegiaram aqueles grupos mais dispostos a dedicar suas energias à arena internacional nos anos $1990^{5}$. (ALVAREZ et al. 2003, p. 551)

Foi nesse período em que as políticas públicas começaram a tratar sobre igualdade de oportunidade

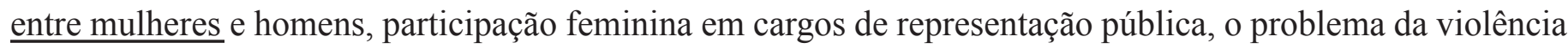
${ }^{3}$ Especialmente central ao início de discussões sobre a mulher no âmbito político.

${ }^{4}$ Para mais informações sobre os Encontros, ver Alvarez et al (2003).

${ }^{5}$ Vale somar a esta citação que nas ultimas duas décadas há uma tendência, no contexto brasileiro, de surgimento de iniciativas que destacam como as opressões podem ser transversais, e que a partir de uma identidade comum se organizam em redes e demandam políticas públicas voltadas para suas especificidades, dentre elas podemos citar a Rede de Mulheres Negras, a Articulação Brasileira de Lésbicas - ABL, o Movimento de Mulheres Camponesas - MMC entre outras (BITTENCOURT, 2015, p. 207-208) 
doméstica, a promoção de direitos reprodutivos, entre outros. É, portanto, neste contexto em que foi gestada a política de cotas legislativas para inclusão de mulheres na política institucional.

\section{UMA VISÃO PANORÂMICA DA REGIÃO: A POLÍTICA DE COTAS NA AMÉRICA LATINA}

As políticas de cotas no legislativo estão entre as principais estratégias dos estados para aumentar a participação feminina em espaços de decisão política. Embora haja uma série de nomenclaturas que as possam caracterizar - ações afirmativas, ações positivas, discriminação positiva -, há um entendimento comum sobre seu objetivo compensatório. Em outras palavras, é finalidade dessa política oferecer tratamento preferencial para grupos que se mostrem historicamente em desvantagem.

Ainda que tenham inspiração nos países escandinavos, as cotas legislativas se disseminaram com maior força nos países da América Latina. Lá a política de cotas não é amparada por legislações como ocorre em muitos países latino-americanos. Lá, cada partido define o percentual mínimo de candidaturas femininas em seu estatuto. Inicialmente, nesses países escandinavos, a iniciativa que garantiria maior acesso às mulheres em ambientes políticos se concentrou em partidos mais à esquerda do espectro político, mas, eventualmente, as políticas também foram adotadas por partidos localizados em todo o gradiente ideológico (JONES, 1998 apud ARAÚJO, 2002). A modalidade intrapartidária de cotas para mulheres, mais comumente conhecida como uma espécie de cota informal, também está presente em países latinos como o Brasil, o Uruguai e a Nicarágua.

Segundo dados do The Quota Project ${ }^{6}$, em 2007 no Chile, a então Presidenta Michele Bachellet apresentou um projeto no qual nem o gênero masculino, nem o feminino poderiam exceder $70 \%$ das posições internas dos partidos políticos, assim como também nas listas de candidatos. No entanto, o projeto ainda não teve resultados positivos, sendo a modalidade de cotas voluntárias em partidos a única medida que visa aumentar a quantidade de mulheres inseridas na política institucional ${ }^{7}$.

Para melhor entendimento, cotas legislativas são, em sua maioria, leis eleitorais ${ }^{8}$ que prevêem determinados percentuais de candidaturas femininas - usualmente entre $20 \%$ e $50 \%$. Além da legislativa, existem ainda as cotas constitucionais, ou seja, aquelas incluídas nos direitos fundamentais de cada cidadão. Como exemplo, temos o caso da Argentina, que primeiro adotou cotas informais no Partido Peronista, em 1945, para só depois lançar a cota como lei eleitoral, em 1991. Na sequência, a transformou em Emenda à Constituição Nacional, em 1994 (MATOS et al., 2007).

Na tabela abaixo, é possível observar o avanço da participação feminina na Câmara Baixa do poder legislativo nacional em todos os países que adotaram, em algum momento, cotas legislativas na América Latina.

\footnotetext{
${ }^{6}$ The Quota Project é uma iniciativa compartilhada entre a organização intergovernamental International IDEA, a Inter Parliamentary Union e Stockholm University que visa compartilhar dados a respeito da criação e implementação da política de cotas no mundo inteiro.

${ }^{7}$ IDEA. The quota Project. Disponível em http://www.quotaproject.org/uid/countryview.cfm?country=45. Acessado em 14.06.2016 ${ }^{8}$ Segundo a base de dados do The Quota Project com exceção da Argentina, República Dominicana e Equador que elevaram a pauta da representação igualitária feminina ao status de uma garantia constitucional, os demais países latino-americanos abordados incluem a política de cotas em suas respectivas leis eleitorais (IDEA, 2016).
} 
Tabela 1 - Representação Feminina no Legislativo ${ }^{9}$ em Países Latino-Americanos que Adotam Política de Cotas

\begin{tabular}{|l|l|l|l|l|l|}
\hline & $\begin{array}{l}\text { Ano das } \\
\text { cotas }\end{array}$ & $\begin{array}{l}\text { Posição IPU'- } \\
2015\end{array}$ & $\begin{array}{l}\text { Representação } \\
1997^{2}\end{array}$ & $\begin{array}{l}\text { Representação em } \\
2015\end{array}$ & Tipo de lista \\
\hline Argentina & 1991 & $20^{\circ}$ & $27,6 \%$ & $36,2 \%$ & Fechada \\
\hline Brasil & $1995^{3}$ & $113^{\circ}$ & $6,6 \%$ & $9,9 \%$ & Aberta \\
\hline México & 1996 & $15^{\circ}$ & $14,2 \%$ & $38,0 \%$ & Aberta/Fechada \\
\hline Paraguai & 1996 & $88^{\circ}$ & $2,5 \%$ & $15 \%$ & Fechada \\
\hline Costa Rica & 1996 & $25^{\circ}$ & $15,8 \%$ & $33,3 \%$ & Fechada \\
\hline Bolívia & 1997 & $2^{\circ}$ & $11,5 \% *$ & $53,1 \%$ & Aberta/Fechada \\
\hline Equador & 1997 & $8^{\circ}$ & $3,7 \%$ & $41,6 \%$ & Aberta \\
\hline Panamá & 1997 & $72^{\circ}$ & $9,7 \%$ & $19,3 \%$ & Aberta/Fechada \\
\hline Peru & 1997 & 58 & $10,8 \%$ & $22,3 \%$ & Aberta \\
\hline República Dominicana & 1997 & $63^{\circ}$ & $11,7 \%$ & $20,8 \%$ & Fechada \\
\hline Venezuela & & & & & Fechada \\
\hline Colômbia & 1998 & $82^{\circ}$ & $5,9 \%$ & $17 \%$ & Aberta/Fechada \\
\hline Honduras & 2000 & $69^{\circ}$ & $11,7 \%$ & $19,9 \%$ & Aberta \\
\hline Uruguai & 2000 & $46^{\circ}$ & $9,4 \% * *$ & $25,8 \%$ & Fechada \\
\hline El Salvador & 2009 & $84^{\circ}$ & $7,1 \%$ & $16,2 \%$ & Fechada \\
\hline
\end{tabular}

Fonte: Elaboração Própria a partir dos dados da Inter-Parliamentary Union- Women in Parliament e do Political Data base of the Americas da Georgetown University.

* Dados sobre Bolívia foram disponibilizados apenas a partir de 1999.

** Dados sobre Honduras foram disponibilizados apenas a partir de 1998.

Como pudemos ver, a Argentina foi o primeiro país a institucionalizar a política de cotas como lei eleitoral, em 1991. Nos anos seguintes, mais quatorze países latinos aderiram às cotas: Brasil (1995), México (1996), Paraguai (1996), Bolívia (1997), Costa Rica (1996), Equador (1997), Panamá (1997), Peru (1997), República Dominicana (1997), Venezuela (1998), Colômbia (2000), Honduras (2000), Uruguai (2009) e El Salvador (2013) (ARCHENTI, 2014). Vale ressaltar que, a concentração de adesões entre os anos de 1996 e 1998 acontece por influência direta do compromisso firmado durante a $4^{\text {a }}$ Conferência Mundial sobre as Mulheres, sediada em Beijing, em $1995^{10}$.

Observando caso a caso, já nos anos 90, a Asamblea Legislativa da Costa Rica lança a lei 7.142, cujo objetivo é a promoção de igualdade social às mulheres. Projeto este que vale ser ressaltado pelo interesse em demonstrar o quanto o machismo apresentava-se como obstáculo à participação feminina na política. Através de normas bem específicas, os partidos foram fortemente encorajados a incluir mulheres em suas listas de candidatos e direções partidárias; além de promover o treinamento das novas candidatas. A lei 7.142 foi responsável pela ampliação do debate público em torno do tema, mas infelizmente, a ausência de obrigatorie-

${ }^{9}$ Para os limites deste artigo optou-se por incluir em nossa análise somente os dados relativos às Câmaras Baixas dos poderes legislativos nacionais. O principal motivo reside em, dos quinze países analisados, sete não contarem com Câmara Altas: Costa Rica, Equador, Panamá, Peru, Venezuela, Honduras e El Salvador (IDEA, 2016). Somando-se a isso, em alguns casos como Brasil e Argentina, há diferença do sistema eleitoral que é proporcional na Câmara Baixa e majoritário nas Câmaras Altas, o que pode indicar peculiaridades específicas no ingresso que merecem especial atenção.

${ }^{10} \mathrm{O}$ resultado do encontro foi um acordo com o objetivo de alcançar a igualdade de gênero e eliminar a discriminação contra mulheres e meninas em todo o mundo. O documento, chamado "Declaração e Plataforma de Ação de Pequim”, listou 12 pontos prioritários de trabalho, além de ações detalhadas para alcançar seus objetivos estratégicos. Em suma, trata-se de um roteiro para o avanço da igualdade e do empoderamento das mulheres nos países. 
dade de suas normas teve pouco resultado efetivo. Apenas em 1996 houve aprovação de cotas no país, com a obrigatoriedade de $40 \%$ de cotas destinadas às mulheres; a maior taxa da América Latina, na época.

Por sua vez, a Venezuela apresenta um caso bastante interessante. Como visto na tabela 1, em 1997, o país estabeleceu cota feminina de 30\% para a Câmara dos Deputados e para o Senado. Posta em prática no pleito de 1998, a representação feminina teve alta de 100\% na participação; passando o contingente de mulheres de 6\% para 12\%. Entretanto, em 2000, a lei foi declarada inconstitucional e passou a não ter validade. Apenas dois partidos contavam com cotas, voluntariamente, de 30\%; Acción Democrática e Movimiento al Socialismo. No entanto, ambos os partidos não mais tiveram representantes eleitos após o ano de $2005^{11}$.

Em caminho diferente, a experiência do Uruguai, um país reconhecido por seu Congresso vanguardista - pela aprovação de políticas públicas de legalização do aborto e em favor do casamento igualitário -, experimentou uma elite parlamentar extremamente refratária à política de cotas. Segundo Peschard (2002), em 1998, quando discutiu-se cotas no Congresso, os legisladores apresentaram posicionamento contrário, por considerarem a intervenção das cotas no tratamento igualitário entre os sexos, inconstitucional. Depois de arquivar inúmeros projetos, a cota legislativa foi aprovada em 2009, com um texto obrigando os partidos a incluir pessoas de ambos os sexos a cada três posições na lista eleitoral, em eleições nacionais e locais; assim como na direção dos partidos. Após muito debate, com oposição feroz às organizações feministas que reivindicavam as cotas, a lei foi aprovada sob a condição de, para cargos nacionais, serem restritas às eleições de 2014 (PERÉZ, 2015).

Embora exista muita dificuldade de implementação, a tabela nos mostra o êxito no aumento de representatividade conferido pelas cotas. No caso da Argentina, primeiro país a aderir à política, é possível observar uma taxa inicial de 6\% de mulheres na Câmara Baixa (LLANOS, 2008 apud BAREIRO, 2013) e um aumento de 21,6 pontos percentuais após seis anos de implementação, em 1997. No ano de 2015, o país contava com uma das maiores médias da região, com $36,2 \%$ de mulheres.

Como observado pela tabela, a Bolívia possui a maior cifra da região; com um aumento de 42 pontos percentuais em 18 anos. O país é o segundo maior em termos de representação feminina no parlamento, dentre 140 nações analisadas pelo IPU-Women in Parliament, em 2015. Além da alta representação feminina da Bolívia ( $2^{\circ}$ lugar), se destacam países como Equador com 41,6\% ( $8^{\circ}$ lugar); México com 38\% (15 lugar), Costa Rica com 33,3\% (25\% lugar) e El Salvador, que apesar de ter implementado a política recentemente, conta com $32,1 \%\left(26^{\circ} \text { lugar }\right)^{12}$. Dentre os quinze países listados, há alguns cujo percentual é intermediário, como a Venezuela com 17\% ( $82^{\circ}$ lugar), o Panamá com 19,3\% (72 lugar), a Colômbia com 19,9\% (69 lugar), a República Dominicana com 20,8\% (63\% lugar), o Peru com 22,3\% (58 lugar) e Honduras com $25,8 \%$ ( $46^{\circ}$ lugar).

Por sua vez, o Uruguai conta com $16,2 \%$ de mulheres no seu parlamento ( $84^{\circ}$ lugar), devido à validez de cotas exclusiva para o pleito de 2014, a representação feminina no país parece estar estagnada. O Paraguai, em 1997, tinha o menor percentual da região com 2,5\% de representantes femininas. Com cotas desde 1996, o país conseguiu subir a representação para $15 \%$, ocupando a $88^{\circ}$ posição do ranking. Se compararmos com seu percentual anterior, é possível observar um avanço interessante; embora em relação à região, sua representação ainda seja baixa.

O país que menos avançou é o Brasil com as cotas funcionando desde 1995, conseguiu subir sua representação em apenas 3,3 pontos percentuais (de 6,6 para 9,9), ocupando a $113^{\circ}$ colocação no ranking do

11 IDEA. The quota Project. Disponível em: http://www.quotaproject.org/uid/countryview.cfm?country=236 Acessado em 14.06.2016.

${ }^{12} \mathrm{O}$ nosso objetivo aqui é discorrer sobre os países com cotas para a câmara baixa do Poder Legislativo nacional, mas vale lembrar que a despeito de não ter a política supracitada Cuba ocupa a $3^{\circ}$ posição do ranking com 48,9\% (IPU, 2016). 
IPU-Women in Parliament. Com lista aberta, com um texto de cotas que não estabelece como elas devem ser aplicadas e penalidade baixa o país não conseguiu que a política emplacasse.

O tema ainda está em debate no país. Em agosto de 2015, por exemplo, o plenário do Senado brasileiro aprovou uma proposta de emenda à Constituição (PEC) que prevê cotas para mulheres nas eleições para os cargos de deputado federal, estadual e vereador. A proposta é que nas três legislaturas seguintes àquela em que a PEC for promulgada tenham pelo menos $10 \%$ de mulheres na primeira legislatura; $12 \%$ na segunda e $16 \%$ na terceira. Apesar de ter passado no Senado, a proposta ainda precisa de mais um turno de votação para aí passar por mais dois turnos na Câmara dos Deputados ${ }^{13}$.

Cabe destacar que os processos de implementação das cotas na América Latina aconteceram paralelamente à discussão na Europa sobre a inserção paritária da mulher no parlamento, isto é, a ocupação de 50\% das vagas. Este debate teve seu ápice na França, com a reforma da Constituição que instituiu a "lei da paridade" em 2000. (ARCHENTI; TULA, 2014)

Quem defende a paridade aponta que ela é uma forma de superar qualitativamente as cotas, por que ao invés de entrar em conflito com o universalismo republicano, ela cria um novo paradigma do que seria o universal; paradigma este que seria, ao mesmo tempo, masculino e feminino ${ }^{14}$. Além de neutralizar a crítica dos que acreditam que as cotas interferem no tratamento igualitário entre cidadãos e cidadãs - por determinar que metade das vagas seja para cada gênero -, a paridade não permite que sejam feitas críticas. Como as referentes a determinação do percentual para a presença mínima de mulheres no Parlamento serem considerado muito aleatório; uma ponderação recorrente entre os opositores da política de cotas.

Archenti e Tula (2014) apontam que existe uma tendência a compreender a paridade como uma política definitiva que efetiva o direito a igualdade entre homens e mulheres, enquanto as cotas são entendidas mais como medidas transitórias. Este debate teve espaço na América Latina na " $X$ Conferencia Regional sobre La Mujer de América Latina y el Caribe” em Quito (2007). Nessa conferência, os países participantes firmaram o Consenso de Quito, um acordo sobre a necessidade de estabelecer a paridade entre os gêneros na região. Em 2010, em Brasília, na "XI Conferencia Regional sobre La Mujer de América Latina y el Caribe” se reafirmou esta prioridade.

Neste contexto é interessante citar que quatro países instituíram uma norma de paridade política nos cargos representativos nacionais recentemente: O Equador o fez constitucionalmente em 2008, a Bolívia e a Costa Rica em 2009 e Honduras em 2012. Argentina (2000), Venezuela (2005 e 2008) e Nicarágua (2012) criaram algumas regras semelhantes, mas para as unidades subnacionais. Apesar de que entre os quatro países que instituíram a paridade só a Bolívia conseguir alcançá-la de fato, vale enfatizar, como disse Bareiro (2013) que esse avanço:

No es un simple cambio numérico", sino una "transformación del sentido mismo de la representación política" que acoge la diversidad y se aleja de los universales construidos por quienes excluyen a otros y otras (GUZMÁN Y MORENO, 2007, p. 32-33 apud BAREIRO et al., 2013 p.66).

É interessante salientar, no entanto, que a paridade também conta com desafios institucionais que, segundo Archenti e Tula (2014), são muito similares aos encontrados nos países que contam com a política de

${ }_{13}$ Disponível em http://g1.globo.com/politica/noticia/2015/08/senado-aprova-em-primeiro-turno-cota-para-mulheres-no-legislativo.html. Acessado em 10.06.2016.

${ }^{14}$ Archenti e Tula (2014) salientam que apesar e ter diversos benefícios em relação às cotas a paridade também sofreu críticas por instituir um universalismo binário que mantêm a limitação para outras diversidades como a de classe, religiosa, raça entre outras. 
cotas. Como detalharemos na sessão seguinte, eles envolvem fatores como a magnitude do distrito, o tipo de lista e o texto normativo ser obrigatório ou não. Archenti (2014) adiciona ainda o papel dos tribunais eleitorais e sua postura para fazer valer as regras de igualdade e gerar jurisprudência, para o caso de haver algo não previsto na lei.

Com este avanço tão valoroso da paridade, na próxima sessão discorremos sobre quais fatores a literatura indica como sendo principais entraves para que as políticas de cotas sejam exitosas.

\section{OS PRINCIPAIS DESAFIOS DAS COTAS NA AMÉRICA LATINA}

Com o panorama da sessão anterior, pudemos perceber como as cotas não apresentaram impacto homogêneo na representação feminina dos países em questão. Em suma, isso se dá principalmente pelos seguintes fatores: (i) a forma da lei; (ii) o sistema eleitoral; (iii) a estrutura partidária; (iv) a capacitação das mulheres.

O primeiro ponto, a forma da lei, diz respeito ao texto das cotas em si. Eles podem ser tratados pelos agentes de forma "obrigatória" ou indicativa. Para o texto ser obrigatório efetivamente, ele não pode estabelecer apenas o percentual, é preciso haver um detalhamento sobre como a cota tem que ser aplicada e principalmente as penalidades caso as regras não sejam seguidas.

Na prática, é a penalidade o que torna a cota obrigatória. Um exemplo disso é o partido não conseguir lançar a candidatura se o percentual mínimo determinado pela cota não for cumprido. Isso acontece na Bolívia e na Argentina. Outro bom exemplo de texto que obriga os partidos a efetivarem a política pública é o da Costa Rica. Como mencionamos na sessão anterior o novo Código Eleitoral de 2009 inclui o princípio da paridade. $\mathrm{O}$ artigo é bem específico deixando claro que os nomes dos candidatos e candidatas devem estar alternados na lista e nos casos que forem números ímpares de candidaturas, a diferença entre homens e mulheres não pode ser superior a um (ARCHENTI, 2014). A sanção também é clara: os partidos que não respeitarem esta norma não terão a lista de candidatos aceita.

As cotas se tornam indicativas, quando elas estabelecem o percentual, sem especificar a forma que ele deve ser alcançado, sendo entendida mais como uma sugestão que pode ser acatada ou não pela direção do partido. Archenti (2014) indica que, na maioria dos casos, os partidos lançam o mínimo de candidaturas femininas permitidas pelas cotas; colocando as mulheres como suplentes ou no final da lista. Além da possibilidade da legislação das cotas ser fraca, no sentido de ser só indicativa, o próximo ponto sintetiza as principais dificuldades que a política pode encontrar para ser efetivada: o sistema eleitoral do país em questão (HTUN, 2001).

Começando pelo tipo de lista. $\mathrm{Na}$ lista fechada o partido coloca a ordem dos candidatos na sua lista. Os eleitores votam no partido e o número de votos que este receber define quantos candidatos são eleitos. São exemplos de países com lista fechada a República Dominicana, o Paraguai e a Venezuela. Já na lista aberta, os eleitores votam diretamente no candidato, e são os votos individuais que garantem a vaga no parlamento. Aqui a eleição gera uma competição do candidato com os demais concorrentes, sendo estes do seu partido ou não. Essa é a dinâmica presente no Brasil e Equador (HTUN, 2001).

A lista fechada e bloqueada tem se tornado a forma por excelência de facilitar a entrada da mulher. Quando a lista é só fechada, sem bloqueio, o partido pode lançar uma lista com mulheres nas primeiras posições, mas depois de eleito passá-las para suplência por exemplo. Quando a lista é aberta, como o voto é direto na candidata ela precisa lidar com a alta competitividade das candidaturas, o que privilegia os candidatos com mais recursos, com mais experiência, com articulação política e com tempo integral para dedicar à campanha. Os candidatos que tem acesso a estes fatores geralmente são homens (RODRIGUES, 2005). Araújo (2010) aponta que a fraca legislação (cota indicativa) que não penaliza os partidos que não cumprem com a cota e a 
lista aberta ${ }^{15}$ são reconhecidas como principais dificuldades pela maior parte dos pesquisadores da área. Há certo consenso também sobre o efeito da magnitude do distrito sobre as cotas.

A literatura aponta que, quando a magnitude de distrito é pequena dificulta para as candidatas mulheres por que há menos vagas. Se há poucos cargos na disputa, o partido geralmente preza por investir no candidato que tem maior possibilidade de ter sucesso, o que leva a dar mais destaque aos candidatos já estabelecidos, que encabeçam listas e que, em geral, são homens. (NORRIS 1993, RULE, 1987 apud ARCHENTI, 2014). Sendo assim, quanto maior a magnitude do distrito, maior o número de candidatos e maior a possibilidade de lançar mulheres (PESCHARD, 2002; HTUN 2001).

É interessante lembrar que as experiências de cotas foram sendo aperfeiçoadas com seu funcionamento. Archenti (2014) aponta que o mandato de posição foi uma mudança fundamental na regra para garantir que as mulheres fossem eleitas. $\mathrm{O}$ mandato de posição funciona da seguinte forma: nos sistemas de lista fechada os partidos apresentam suas listas com os candidatos ordenados numericamente. A quantidade de votos que a legenda recebe é a quantidade de deputados que ela vai eleger. Se receber 30\% dos votos com listas de 10 pessoas elegerá apenas três pessoas. Neste sentido não basta que as mulheres estejam presentes na lista, é preciso que elas estejam bem colocadas.

O mandato de posição foi fundamental no caso da Costa Rica. Na primeira eleição com cotas, os partidos colocaram as mulheres em lugares irrelevantes na lista. Com isso, o percentual de eleitas foi de 19,3\%. Ante o baixo crescimento, criou-se o mandato de posição, uma decisão do Tribunal Eleitoral de 2002 que obrigava os partidos a colocarem as candidatas em posições elegíveis, com isso na eleição seguinte o percentual de eleitas é de 35,1\%, sendo seguido por 38,6\% nas eleições de 2006 e 2010 (PESCHARD, 2002; TORRES, 2010). Como veremos no excerto a seguir, o terceiro fator apontado como relevante pela literatura é a dinâmica interna os partidos, uma vez que o processo interno de seleção é fundamental para as mulheres terem chances reais nas câmaras legislativas.

\begin{abstract}
La experiencia en la aplicación de mecanismos que propicien la participación y representación política de las mujeres, ha demostrado que es más probable que ellas resulten beneficiadas si el partido político tiene procedimientos regulados y definidos de selección de candidaturas, en lugar de un sistema de "lealtad" e "influencias" hacia quienes se encuentran en el poder. Un desafío adicional para los partidos, es el cumplimiento de la obligación de utilizar el financiamiento estatal en la capacitación política (en período electoral y no electoral), de manera paritaria (TORRES, 2010 p. 7).
\end{abstract}

Reivindicar que as organizações partidárias tenham uma dinâmica democrática interna nas organizações partidárias é fundamental, não só para que as mulheres consigam se incluir na competição e não serem suplantadas pelos candidatos homens que já tem maior capital político dentro da organização, mas para toda e qualquer pessoa nova na organização partidária que precisa acumular capital político para se inserir na disputa partidária.

O quarto fator destacável, que também aparece no excerto acima, é a capacitação das candidatas. Araújo (2002) constata que as cotas, são a forma de ação política escolhida pelos partidos para catalisar as pressões por paridade recebidas. No entanto, é importante salientar que as instituições partidárias podem transcender essa medida e investir parte de seu orçamento em formação, em especial das militantes, para que estas possam acumular capital político para entrar não apenas na lista de candidatos, mas também em cargos de direção partidária.

${ }^{15}$ A autora ressalta que a lista aberta é um fator limitador reconhecida pelos pesquisadores, mas não é consensual que ela seja definidora. (ARAUJO, 2010). 
Embora o debate sobre capital político não seja o enfoque deste artigo, consideramos importante ressaltar que a relação estabelecida entre o capital e a possibilidade de êxito na carreira é direta. Isso significa que, não ter capital, seja ele político, financeiro, acadêmico, limita as possibilidades de ascensão do agente (PINHEIRO, 2006). No que diz respeito ao capital político, podemos afirmar que é composto por uma série de recursos que revestem o agente de legitimidade para a atuação na arena política. Em um primeiro momento, ascender na política institucional depende da conquista de uma base eleitoral, mas não só. Possuir reconhecimento de seus pares é fundamental para sucesso de apoio na candidatura e êxito na concorrência por postos mais relevantes dentro do parlamento.

Quando falamos especificamente em ingresso de mulheres na política, o tempo se apresenta enquanto recurso imprescindível. De acordo com Miguel e Biroli (apud MARQUES, 2012), o gasto de campanha entre mulheres e homens não parece variar, mas o tempo livre aparece enquanto diferença crucial entre os gêneros. Uma das causas desse fenômeno pode ser observada na persistente desigualdade na divisão do trabalho doméstico, que acaba por tomar muito mais o tempo de mulheres do que de homens. Embora seja assunto recorrente, as jornadas duplas e triplas, enfrentadas pelas mulheres no cuidado com as crianças e idosos e com os afazeres domésticos, dificultam o envolvimento aprofundado em atividades políticas (MARQUES, 2012 p. 36). Em seu trabalho, Marques (2012) ressalta que, mesmo em arranjos familiares contemporâneos, a participação masculina permanece enquanto "ajuda"; dificultando o entendimento de co-responsabilização igualitária do trabalho doméstico.

É também válido lembrar que existe uma ideia generalizada que associa a entrada de mulheres no âmbito político a apadrinhamento familiar. Como apontam estudos, a entrada de mulheres na carreira política se dá, majoritariamente, através de movimentos sociais ou por parentesco - como filhas ou esposas de políticos homens (BARREIRA, 1998; GROSSI E MIGUEL, 2001; COSTA, 2001; AVELAR, LÚCIA. 2001; RODRIGUES, 2002; ARAÚJO, 2001 apud PINHEIRO 2006). No entanto, Miguel et al (2015) salientam que, muitas vezes, pesquisas que abordam o capital familiar em sucesso eleitoral, enfocam apenas em parlamentares mulheres; não apresentando dados sobre a influência do capital familiar na entrada de homens na política. Percebe-se através dessa lacuna, a necessidade de pesquisas que realizem trabalho de comparação, com o objetivo de melhor compreender os mecanismos em torno da participação de mulheres na política.

Levando em consideração que vários fatores, que fogem às regras institucionais, influenciam a entrada, a permanência e o êxito das mulheres na política, torna-se válido retomar o exemplo das nações escandinavas; mencionadas anteriormente. Nessas nações, o aumento da participação feminina não só é capitaneado pelas cotas voluntárias, como as mulheres contam com a sustentação de um estado de bem-estar social dotado de políticas que facilitam sua participação. Somando essas iniciativas à uma já alta participação política feminina, há o apoio de uma cultura política igualitária arraigada, que faz com que os partidos se sentam mais compelidos a cooperar (ARAÚJO, 2002).

Para além da mudança das regras eleitorais e dos partidos, e visando o alcance de paridade efetiva na América Latina, é fundamental que as cotas venham acompanhadas de políticas estruturais que garantam acesso paritário à educação, a saúde e ao trabalho. É preciso de respaldo do Estado para garantir creches, seguro desemprego, centros de atenção à criança, licença maternidade. É preciso também que a sociedade civil, em especial os movimentos feministas, se mantenham alertas, reivindicando e exercendo um controle cidadão na implementação e avaliação destas políticas. Para apoiar estes processos, torna-se essencial uma geração de informação e de análises da sociedade civil organizada, dos meios de comunicação e principalmente da academia sobre o andamento destes processos de inclusão das mulheres na política institucional. 
Na realidade, as cotas “[...] son solo puntas de lanza que preparan el terreno para que se desarrollen políticas y programas públicos de atención a las demandas de las mujeres" (PESCHARD, 2002 p. 184). Sendo assim, é preciso aproveitar o caminho aberto por elas para reivindicar políticas de paridade efetivas não só na representação na política institucional, mas em todas as esferas da sociedade.

\section{CONSIDERAÇÕES FINAIS}

O presente artigo procurou observar a maneira através da qual cotas legislativas foram implementadas na América Latina; assim como seus principais resultados e maiores desafios. A partir da pesquisa, pudemos perceber que o processo de cotas esteve diretamente associado à pressão exercida pelas organizações feministas de cada país, associados à pressão da agenda internacional sobre o tema. Tendo o contexto acima em vista, independente do sucesso da política pública em si, as cotas legislativas foram importantíssimas para conferir destaque ao problema da sub-representação feminina.

Nesse sentido, é possível afirmar que as cotas, embora, de modo geral, tenham aumentado a representação de mulheres nas regiões estudadas, esse processo se deu de maneira bem heterogênea. Enquanto alguns países conseguiram alcançar bons percentuais - como Bolívia, Equador, México, Argentina e Costa Rica -, a maioria ainda apresenta percentuais inferiores a $25 \%$. O resultado desse quantitativo mostra que, em vez de agir como plataforma mínima, a cota legislativa tem sido utilizada como teto de representação.

No decorrer do texto, pudemos observar que há regras que facilitam o sucesso das cotas - como é o caso do mandato de posição, da magnitude do distrito eleitoral maior e da lista fechada e bloqueada -, no entanto, encontramos algumas exceções. No caso das listas, por um lado, vimos que o Equador, utilizando o sistema de lista aberta, conta com 41,6\%. Por outro lado, Paraguai apresenta apenas 15\% de representação feminina, com lista fechada. Para explicar casos como estes, o ideal é que este estudo possa continuar a análise de cada país. Apenas através de profundo diagnóstico, poderemos averiguar os fatores de real influência para o aumento da representação feminina.

Por fim, cabe salientar que cotas, por si, não dão conta de incluir as mulheres na política. As desigualdades de gênero geralmente são amparadas por processos muito mais complexos que os institucionais. É preciso de políticas públicas que promovam a igualdade também na cultura política, na família, nas instituições religiosas, no mundo do trabalho, na representação da mulher na mídia entre outras.

\section{REFERÊNCIAS BIBLIOGRÁFICAS}

ALVAREZ et al. "Encontrando os feminismos latino-americanos e caribenhos". Revista Estudos Feministas, Florianópolis, 11(2): 360, julho-dezembro/2003.

ARAÚJO, Clara. “Ações afirmativas como estratégia política feminista”. In: BRUSCHINII, Cristina; UNBEHAUM, Sandra (orgs.). Gênero, democracia e sociedade brasileira. São Paulo: Fundação Carlos Chagas/Ed. 34, 2002.

ARAÚJO, Clara. "Rotas de ingresso, trajetórias e acesso das mulheres ao legislativo - um estudo comparado entre Brasil e Argentina". Revista Estudos Feministas, Florianópolis: 2010. 18(2): 352, maio-agosto. ARCHENTI, Nélida. "El proceso hacia la paridad en América Latina. Argentina y Costa Rica, experiencias comparadas" IN: Revista de Derecho Electoral, N. ${ }^{\circ}$ 17, Enero-Junio, 2014.

ARCHENTI, Nélida; Tula, Maria Inés. "Cambios normativos y equidad de género. De las cuotas a la paridad en América Latina: los casos de Bolivia y Ecuador” IN: América Latina Hoy, núm. 66, enero-junio, 
2014, pp. 47-68,2014

BAREIRO et al. "La ciudadanía de las mujeres en las democracias de las Américas". Comisión Interamericana de Mujeres. OEA documentos oficiales; OEA/Ser. 2013.

BITTENCOURT, Naiara Andreoli. “Movimentos Feministas”. Revista Insurgência. Brasília Ano 1, v.1, n.1, jan./jun, 2015.

HTUN, Mala. “A política de cotas na América Latina”. In: Estudos Feministas, 2 25 1/2001.

IDEA Internacional. Quota Project: Global Data base of Quotas for Women. Disponível em: http://www.quotaproject.org/. Acesso em: 16. jun. 2016

INTER-PARLIAMENTARY UNION. Women in national parliaments: World classification.16.06.2016. Disponível em: http://www.ipu.org/wmn-e/classif-arc.htm. Acesso em: 16.06.2016

MARQUES, Danusa. "Determinantes de carreiras políticas no Brasil, na Argentina e no Uruguai: uma abordagem comparativa entre deputadas e deputados". Tese (Doutorado). Universidade Federal de Minas Gerais - UFMG. Brasília, 2012.

MATOS, Marlise; Cypriano, Breno; Brito, Marina. "Cotas de Gênero para o reconhecimento das Mulheres na Política: Um estudo comparado ações afirmativas no Brasil, Argentina e Peru”. IN: Anais do XIII Congresso Brasileiro de Sociologia, Recife-Brasil. 2007.

MIGUEL, Luis Felipe; MARQUES, Danusa; MACHADO, Carlos. "Capital Familiar e Carreira Política no Brasil: Gênero, Partido e Região nas Trajetórias para a Câmara dos Deputados”. Revista Dados, v. 58, p. $721-747,2015$.

PÉREZ, Verónica. "Las mujeres en política en Uruguay. De la cuota a la paridad: una reforma necesaria". Facultad de Ciencias Sociales. Universidad de la República, Uruguay. Policy paper №5. 2015.

PESCHARD, Jacqueline. “El sistema de cuotas en América Latina. Panorama general”. In: International IDEA Mujeres en el Parlamento. Más allá de los números, Stockholm, Sweden. 2002.

PINHEIRO, Luana Simões. "Vozes femininas na política: uma análise sobre mulheres parlamentares no pós-constituinte". Dissertação (Mestrado). Universidade de Brasília- UNB. Brasília, 2006. Disponível em: http://repositorio.unb.br/handle/10482/2121?mode=full

RODRIGUES, Almira. "Lugar de mulher é na política: um desafio para o século XXI" In: Mulheres em ação: práticas discursivas, práticas políticas. SWAIN, Tânia Navarro; MUNIZ, Diva do Couto Gontijo (Orgs.). Florianópolis: Ed. Mulheres; Belo Horizonte: Ed. da PUC Minas, 2005.

TORRES, Isabel García. “Costa Rica: sistema electoral, participación y representación política de las mujeres”. UN-INSTRAW, República Dominicana. Agosto, 2010.

VALDÉS, Tereza. "Estudios de Género: una Mirada evaluativa desde el cono sur". IN: ARANGO, Luz Gabriela; Puyana, Holanda. Género, Mujeres y Saberes en América latina: Entre el movimiento social, la academia y el Estado. Colombia: Universidad Nacional de Colombia - Bogotá, 2007.

(Footnotes)

1 IPU é a sigla de Inter Parliamentary Union, uma organização internacional de Parlamentos fundada em 1889. Dentre as diversas informações disponibilizadas por esta plataforma está a base de dados Women in Parliament, que mede a representação feminina em Parlamentos desde 1997 até hoje. 
21997 é o ano da primeira série temporal do IPU-Women in Parliament.

3 Segundo Rodrigues (2005) no Brasil a cota começou em 1995 reservando 20\% das candidaturas em eleições proporcionais para as mulheres, este texto foi revisado em 1997, adotando um percentual mínimo de $30 \%$ e máximo de $70 \%$ para ambos os sexos. 